\title{
Integral Test Facilities and Thermal-Hydraulic System Codes in Nuclear Safety Analysis
}

\author{
Klaus Umminger ${ }^{1}$ and Alessandro Del Nevo ${ }^{2}$ \\ ${ }^{1}$ AREVA NP GmbH, Paul-Gossen Strasse 100, 91052 Erlangen, Germany \\ ${ }^{2}$ ENEA UTIS-TCI, C.R. Brasimone, 40032 Camugnano (Bo), Italy \\ Correspondence should be addressed to Klaus Umminger, klaus.umminger@areva.com
}

Received 1 December 2011; Accepted 1 December 2011

Copyright (C) 2012 K. Umminger and A. Del Nevo. This is an open access article distributed under the Creative Commons Attribution License, which permits unrestricted use, distribution, and reproduction in any medium, provided the original work is properly cited.

A considerable amount of resources has been devoted at the international level during the past three decades for establishing and conducting experimental programmes in scaleddown integral test facilities (ITFs). These were aimed at solving open issues for current nuclear power plant (NPP), demonstrating the technical feasibility of innovative designs, and generating reference databases to support code development and assessment. Since the end of the nineties, the maintenance of the competences of experienced research teams as well as the creation of a new generation of professionals in the area of the nuclear safety is also a priority objective of operating research facilities and promoting experimental programmes.

Tens of ITFs have been built and operated so far all over the world. Few of them, related to existing water reactor technology, are currently in operation (e.g., ATLAS, PMK, PKL-III, ROSA/LSTF, INKA) or under refurbishment (e.g., PACTEL, PSB-VVER). Some others are constructed or under design and are focused on innovative water reactor concepts (e.g., MASLWR, SPES-3).

The experimental data from such facilities are applicable to full-scale nuclear plant conditions; if the test facilities and the initial and boundary conditions of experiments are properly scaled, for example, the scaling will not affect the evolution of physical processes important for the postulated accident scenario. This evaluation determines whether the data may be used in nuclear plant safety analyses of a postulated accident.

On the other side, the experimental data are fundamental for supporting the development and demonstrating the reliability of computer codes in simulating the behavior of an
NPP during a postulated accident scenario: in general, this is a regulatory requirement. The reliance on computer codes, among the other things, is based on the reason that, very often, one cannot directly apply results from test facilities to a plant, including the "reference" plant of the facility design.

Applications of computer codes to accident analyses require the implicit assumptions that these codes have the capabilities to scale up phenomena and processes from test facilities to full-scale plant conditions. However, the different scale, in terms of geometry, characterizing any facility and a nuclear plant does not ensure a priori that a code, which is able to reproduce a generic transient in a scaled facility, is also able to calculate with the same accuracy the same transient in NPP.

The aforementioned topics involve a number of key activities, in which the research is taken up. This special issue documents the present scientific and technical status and recent advances in relation to the ITF, the experimental programmes, the issues connected with the code assessment, and the scaling issue, which is related both to the representativeness of the phenomena in the facilities as well as the applicability of the codes.

The special issue collects 17 papers, which are divided into 4 main groups, according to the following rationale: (1) Western PWR technology (8 papers), (2) Eastern PWR (or VVER) technology (4 papers), (3) BWR technology (3 papers), and (4) innovative, integral-type, water reactor concepts (2 papers).

The paper by $\mathrm{K}$. Umminger et al. presents the PKLIII integral test facility and provides a survey of test objectives and programs carried out to date as well as plans for 
future investigations. The authors point out important results achieved in improving the level of understanding of the PWRs system response under accident conditions as well as of the thermal-hydraulic phenomena relevant for the nuclear reactor safety and the importance for code validation.

Then, K. Y. Choi et al. describe ATLAS integral test facility, the main findings, and lessons learned obtained using the data of the past integral effect tests. The paper discusses also the future prospects of the application of ATLAS facility in the framework of national nuclear R\&D program in Korea.

T. Takeda et al. discuss the analysis of a PWR loss of feedwater (LOFW) by means of a ROSA/LSTF experiment conducted for the OECD/NEA ROSA project and the application of RELAP5 code. The description of relevant phenomena of the transient and the results of assessment of the code are reported in the paper.

C. Addabbo and A. Annunziato illustrate the LOBI facility project. The paper provides a historical perspective and summarizes major achievements of the research programme which has represented an effective approach to international collaboration in the field of reactor safety research and development. Focus is also given to the issue of the management of research data.

The paper of J. Freixa and A. Manera addresses the issue of the validation process of system codes for the transient analyses of PWR. Five posttest analyses by TRACE code are presented. They are related to small and intermediate LOCA experiments executed in ROSA/LSTF integral test facility. The paper underlines the relevance of the validation activity in relation to the modeling of an NPP for safety analysis purposes.

A. Bousbia Salah and J. Vlassenbroeck present the analysis of three experimental tests performed in PKL-III integral test facility, executed in the framework of the OECD/NEA PKL-2 project. The tests are devoted to the study of the cooldown procedures operated after the reactor trip in order to bring the primary side temperature and pressure to the residual heat removal system (RHRS) operating conditions. The objective is to assess the impact of a chosen cool-down strategy upon the occurrence of natural circulation interruption (NCI) and the capabilities of CATHARE2 code in predicting such process. Relevance is given to the interaction between the key parameters governing the transient and the phenomena involved.

F. Reventós et al. analyze the results of three posttest calculations of the $L O B I$ integral test facility experiments. The selected experiments are LOCA scenarios of different break sizes and with different availability of safety injection components. The objective of the analysis is to improve the knowledge of the phenomena reproduced in the facility in order to use them for nodalization qualification purposes of nuclear power plants or for establishing accuracy databases for uncertainty methodologies.

The last paper of the Western PWR technology group by A. Prošek discusses the assessment of how the accuracy of a simulation depends on the code version used. The code selected is RELAP5, widely used all over the world for safety analysis of nuclear power plants. The study is based on an experimental test executed in the BETHSY integral test facility, identified as 9.1b, which is the OECD International Standard Problem no. 27.

A. Del Nevo et al. discuss a benchmark activity among different thermal-hydraulic system codes (i.e., ATHLET, RELAP5-3D, KORSAR, and TECH-M) and institutions performed on the basis of the PSB-VVER integral test facility data. The activity is preformed in the framework of the OECD/NEA PSB-VVER project. The objective is to collect, analyze, and document the numerical activity (pre- and posttest) performed by the participants, describing the performances of the code simulations and their capabilities to reproduce the relevant thermal-hydraulic phenomena observed in the experiment.

G. Ézsöl et al. illustrate the $P M K-2$ facility, which was the first integral-type facility for VVERs. The paper gives comprehensive information on the design features of PMK-2 facility with a special respect to the representativeness of phenomena, the experiments performed, and the results of the validation of ATHLET, CATHARE2, and RELAP5 codes. It discusses also the safety significance of the PMK-2 projects.

The paper by V. Kouhia et al. describes the construction and the experimental research activities of two integral test facilities: the former, PACTEL, devoted to the simulation of VVER-440 NPP and the latter, PWR-PACTEL, for research activities associated with the $\mathrm{EPR}^{\mathrm{TM}}$ reactor. The OECD International Standard Problem no. 33 and the PWRPACTEL benchmark launched in 2010 are presented as sample activities.

V. Blinkov et al. present three LB LOCA tests, two MSLB tests, and one SB LOCA test carried out in the integral test facility $B C V-213$, which represents the bubble condenser system of Kola NPP (Unit 3). The paper provides information about the application of ATHLET code for supporting the design of the experiments and, then, describes in detail the validation activity related to the COCOSYS code.

The paper of D. Paladino and J. Dreier is focused on the multipurpose facility PANDA. The applications cover integral containment response tests, component tests, primary system tests, and separate effect tests. The paper provides an overview of the research programs performed in relation to BWR containment systems and those planned for PWR containment systems.

S. Leyer and M. Wich describe the INKA (integral test facility Karlstein) test facility, which was designed and constructed to test and demonstrate the performance of the passive safety systems of KERENA, the new AREVA boiling water reactor (BWR) design. The authors discuss the facility features and capabilities, the instrumentation systems, and the experimental program. INKA is within the KERENA development program devoted to single component/system tests of the emergency condenser, the containment cooling condenser, and the passive core flooding system. The paper outlines the integral system tests, which will be performed to simulate transients and LOCA (loss of coolant accident) scenarios. These experiments will involve the testing of the KERENA Passive Pressure Pulse Transmitter System.

S. Racca and T. Kozlowski present a validation activity carried out with TRACE code related to the simulation of spray cooling injection in a BWR reactor. The data, acquired 
by experiments of the Swedish GÖTA test facility, are compared with the results derived from the code modeling. Focus is given to the countercurrent flow limiting (CCFL) phenomenon. The activity includes the application of the propagation of input errors (PIEs) method, which is used to perform the uncertainty analysis and to identify the input parameters having more influence on the figure of merit selected (in this case the peak cladding temperature).

The first paper of the innovative (integral-type) water reactor concepts group by F. Mascari et al. describes the integral test facility MASLWR. The multiapplication small lightwater reactor (MASLWR) is the scaled-down model of a small modular PWR, relying on natural circulation during both normal and accident conditions. The paper includes a review of the main characteristics of the facility and summarizes the tests already executed and the related code validation activity. Finally, the reader can find information on the IAEA International Coordinated Research Program, currently ongoing, based on the MASLWR experimental tests.

The paper of A. Achilli et al. presents the SPES-3 integral test facility. It is designed by SIET to simulate the W-IRIS reactor concept under normal and accident conditions. The authors give an overview of the design of the test facility underlining the uses of RELAP5 and RELAP5/GOTHIC coupled codes for the achievement of the final scaling concepts and layout of the facility.

In conclusion, the scientific and technical contributions from the authors provide the readers with useful information related to 14 experimental facilities and cover a broad spectrum of the recent past and current activities dedicated to this special issue.

\section{Acknowledgments}

The guest editors acknowledge all authors who have submitted papers to this special issue. Special thanks are due to our colleagues for the kind collaboration in reviewing these papers.

Klaus Umminger Alessandro Del Nevo 

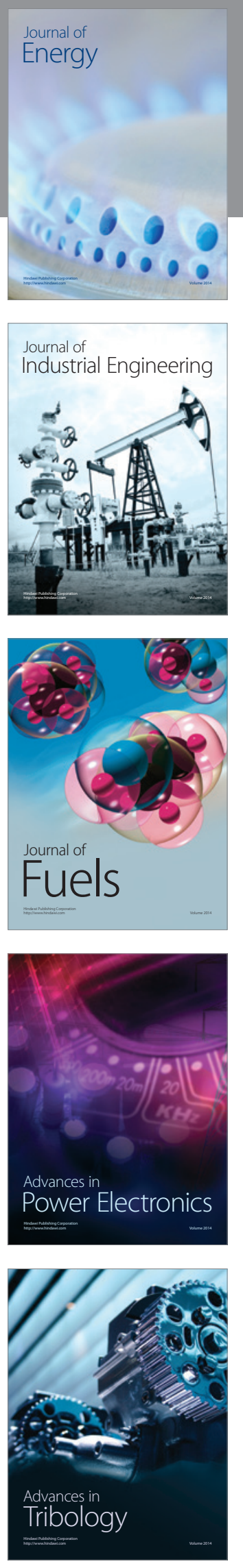
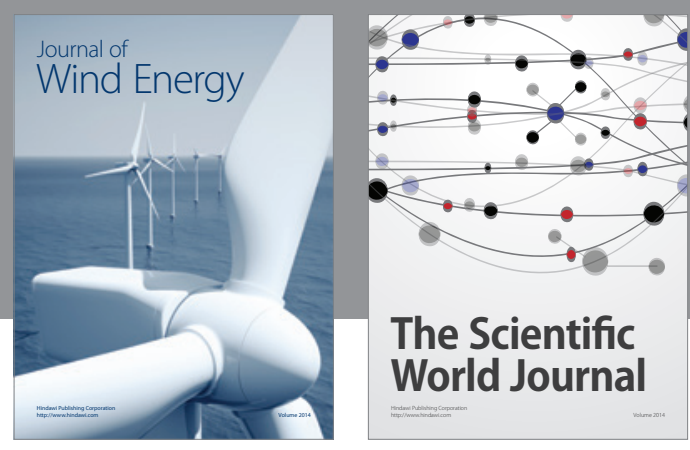

The Scientific World Journal

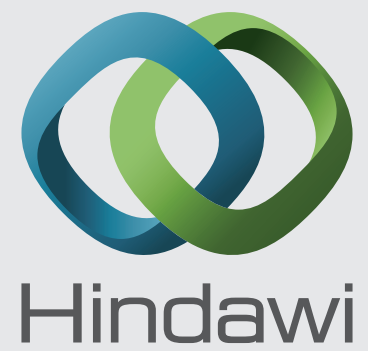

Submit your manuscripts at http://www.hindawi.com
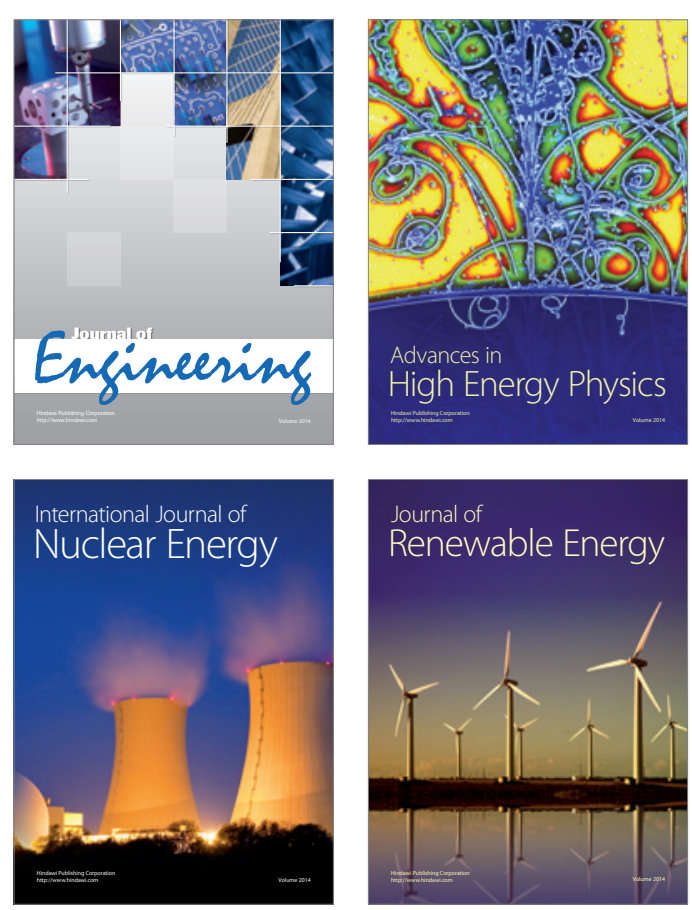

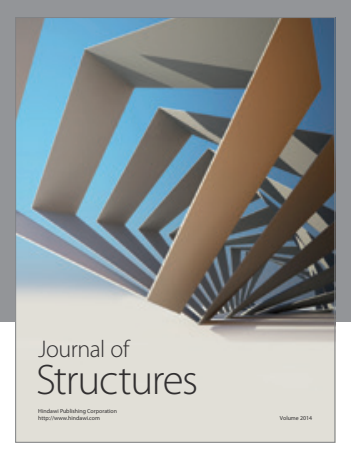

Rotating
Mechinery
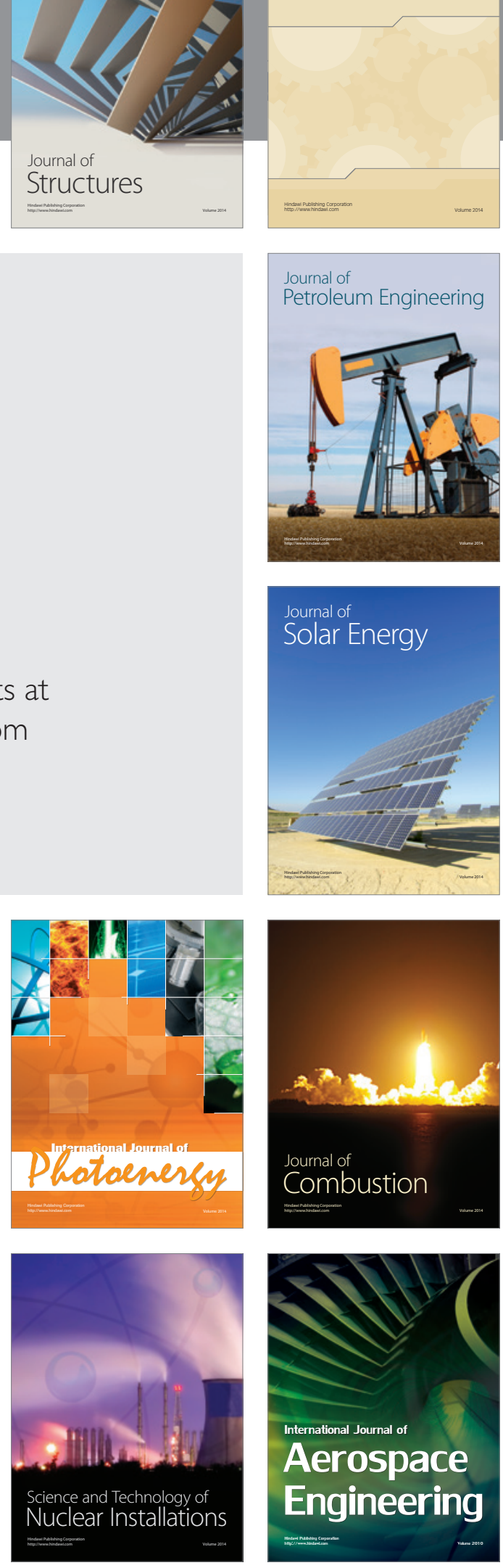